\title{
Predictors of 25-hydroxyvitamin D status among adults in two British national surveys
}

\author{
Vasant Hirani ${ }^{1}$, Annhild Mosd $\varnothing 1^{2}$ and Gita Mishra ${ }^{1}$. \\ ${ }^{1}$ Department of Epidemiology and Public Health, Royal Free and University College London Medical School, University College \\ London, 1-19 Torrington Place, London WC1E 6BT, UK \\ ${ }^{2}$ Section for Food Studies and Public Nutrition, Akershus University College, PO Box 423, 2001 Lillestrøm, Norway
}

(Received 14 August 2007 - Revised 30 May 2008 - Accepted 5 June 2008 - First published online 17 July 2008)

Several recent reports have found a high prevalence of vitamin D deficiency in the adult British population. The present paper investigates the associations of low income/material deprivation and other predictors of serum 25-hydroxyvitamin D (25(OH)D) status in two surveys: The National Diet and Nutrition Survey (NDNS) of the population aged 19-64 years in mainland Britain and the Low Income Diet and Nutrition Survey (LIDNS) of adults aged $\geq 19$ years in all regions of the UK who were screened to identify low-income/materially deprived households. A valid serum 25(OH)D sample was obtained in 1297 and 792 participants from the NDNS and LDNS respectively. The NDNS participants who were not receiving benefits $(n$ 1054) had a mean $25(\mathrm{OH}) \mathrm{D}$ of $50 \cdot 1 \mathrm{nmol} / 1$, which was higher than among NDNS participants receiving benefits ( $n$ 243) with a mean $25(\mathrm{OH}) \mathrm{D}$ of $43.0 \mathrm{nmol} / \mathrm{l}(P<0.001)$ and the LIDNS sample $(46.5 \mathrm{nmol} / \mathrm{l} ; P<0 \cdot 05)$. For all three samples, the season of drawing blood, skin colour, dietary intake of vitamin $\mathrm{D}$, and intake of dietary supplements were significant predictors $(P<0 \cdot 05)$ of serum $25(\mathrm{OH}) \mathrm{D}$ status in mutually adjusted regression models. National prevention and treatments strategies of poor vitamin D status need to be targeted to include the adult population, particularly deprived populations, in addition to the elderly and ethnic minorities.

\section{5-Hydroxyvitamin D status: Adults: Low income: Population surveys}

Sufficient vitamin D is crucial for good bone health, but increasing evidence suggests that it may also play an important role in the prevention of diabetes, cancers, heart disease and other non-communicable diseases ${ }^{(1,2)}$. Vitamin D in the form of cholecalciferol is generated in the skin when exposed to daylight. The amount produced depends particularly on the wavelength and strength of the light and the individual's skin colour $^{(2)}$. Low endogenous production during winter months can be compensated for by dietary intake and supplement use, but vitamin D intake is presently low in Britain ${ }^{(3)}$.

Vitamin $\mathrm{D}$ deficiency has primarily been addressed as a problem among the elderly ${ }^{(2)}$, children $^{(4,5)}$ and ethnic minorities ${ }^{(6,7)}$. However, two recent surveys of British adults, The National Diet and Nutrition Survey (NDNS) of adults aged 19-64 years $^{(3)}$ and the 1958 British birth cohort ${ }^{(8)}$, both report that approximately $15 \%$ of the population had serum 25-hydroxyvitamin D $(25(\mathrm{OH}) \mathrm{D})$ levels below $25 \mathrm{nmol} / 1$ (indicating deficiency) ${ }^{(9)}$. The estimated prevalence of deficiency was somewhat higher in the Low Income Diet and Nutrition Survey (LIDNS), with $23 \%$ of adult men and $18 \%$ of women being below the reference ${ }^{(10)}$. The aim of the present paper was to examine the influence of low income/material deprivation on vitamin $\mathrm{D}$ status and investigate predictors of $25(\mathrm{OH}) \mathrm{D}$ status using data from the NDNS of adults aged 19-64 years and the adult population of LIDNS ( $\geq 19$ years).

\section{Methods \\ Samples}

The LIDNS sample selection followed a multi-staged clustered design using all regions of the UK. The target population was the $15 \%$ most deprived households in the UK and participants were selected based on screening questions aimed at identifying low-income or materially deprived households (combination of questions regarding, for instance, type of housing, car ownership, employment status, receipt of certain benefits or pensions). Up to two respondents (one adult and one child) were selected from a household, excluding pregnant women. Data were collected during 2003-5. Participants aged $\geq 19$ years consisted of 1048 men and 2019 women. Of these, $96 \%$ started the individual questionnaire or the first of four dietary recalls. Ninety percent agreed to be visited by a nurse, $81 \%$ were successfully revisited and $51 \%$ (both sexes) provided a blood sample. A valid serum $25(\mathrm{OH}) \mathrm{D}$ sample was obtained from 246 men and 546 women $^{(10)}$.

The NDNS sample was selected using a multistage random probability design using all postal sectors within mainland Britain. Eligibility was defined as being aged 19-64 years and not pregnant or breast-feeding. One eligible adult per household was selected at random. Data were collected during 2000 and $2001^{(3)}$. Of the 3704 eligible respondents,

Abbreviations: LIDNS, Low Income Diet and Nutrition Survey; NDNS, National Diet and Nutrition Survey; NDNS , NDNS sample receiving benefits; NDNS $_{\mathrm{NB}}$,

NDNS sample not receiving benefits; $25(\mathrm{OH}) \mathrm{D}$, serum 25-hydroxyvitamin D.

* Corresponding author: Dr Gita Mishra, fax +44 207813 0242, email g.mishra@nshd.mrc.ac.uk 
$61 \%$ completed the dietary interview. Participants were asked to provide further measurements, including anthropometry, blood pressure and a urine sample. Blood samples were obtained in $61 \%$ of men and $59 \%$ of women in the dietary sample. A valid serum $25(\mathrm{OH}) \mathrm{D}$ sample was obtained from 592 men and 705 women $^{(11,12)}$.

\section{Blood collection and analysis}

Blood samples were collected non-fasted and analysed for serum $25(\mathrm{OH}) \mathrm{D}$ by the DiaSorin Kit (DiaSorin Inc., Stillwater, MN, USA) for both the NDNS and LIDNS. The laboratories performing the $25(\mathrm{OH}) \mathrm{D}$ analyses took part in the Vitamin D External Quality Assessment Scheme. In these surveys there was no significant change in the assay's performance throughout its use as assessed from quality-assurance parameters $^{(10,11)}$.

\section{Anthropometry and other covariates}

In both studies, interviewers collected data on sociodemographic aspects (including age, sex, ethnicity, region of residence, and season of data collection) and health behaviours (including the intake of vitamin supplements). Height and weight measurements were taken in light clothing without shoes, and BMI $\left(\mathrm{kg} / \mathrm{m}^{2}\right)$ was calculated. Dietary vitamin D intakes were obtained from four $24 \mathrm{~h}$ recalls on random days (including at least one weekend day) in the LIDNS sample ${ }^{(10)}$ and by $7 \mathrm{~d}$ weighed dietary records in the NDNS sample ${ }^{(11)}$.

\section{Statistical analyses}

Simple and multiple regression analyses were used to model the relationships between serum $25(\mathrm{OH}) \mathrm{D}$ as a continuous outcome measure and covariates including age group, ethnicity, sex, region of residence, dietary intake, and dietary supplement use. For the NDNS sample, significant interactions were found for benefit status and season of data collection, BMI, ethnicity, dietary vitamin D intake, and supplement use $(P<0 \cdot 01)$. Therefore the NDNS sample was divided into those receiving benefits $\left(\mathrm{NDNS}_{\mathrm{B}}\right)$ and those who did not $\left(\mathrm{NDNS}_{\mathrm{NB}}\right)$. To assess if the predictors of serum $25(\mathrm{OH}) \mathrm{D}$ in the LIDNS sample were similar to those in other lowincome groups, analysis was carried out separately for the three samples, LIDNS, $\mathrm{NDNS}_{\mathrm{B}}$, and $\mathrm{NDNS}_{\mathrm{NB}}$. Descriptive statistics were weighted to correct for the sampling probabilities and non-response in the two surveys ${ }^{(10,11)}$. For all the three samples, the 'skewness index' for the distribution of serum $25(\mathrm{OH}) \mathrm{D}$ was between 0.5 and 0.8 samples, and hence there was no need to transform the variable before analysis.

\section{Results}

Participants in the $\mathrm{NDNS}_{\mathrm{NB}}$ sample had a mean 25(OH)D of $50 \cdot 1 \mathrm{nmol} / 1$, which was significantly higher than among the $\mathrm{NDNS}_{\mathrm{B}}$ sample $(43.0 \mathrm{nmol} / \mathrm{l} ; P<0.001)$ and the LIDNS sample ( $46.5 \mathrm{nmol} / \mathrm{l} ; P<0.05)$. There was no significant difference between the two latter samples. The mean serum $25(\mathrm{OH}) \mathrm{D}$ concentrations were not significantly different between men and women within each of the three samples, nor across age groups. There was a marked seasonal variation in all three populations, with the mean levels being approximately $50 \%$ higher for blood samples collected in July-September compared with January-March. Serum 25(OH)D concentrations were also strongly associated with ethnic group and supplement use in the expected manner. In all three samples dietary vitamin D intake (three levels) was associated with serum $25(\mathrm{OH}) \mathrm{D}$ levels. The proportion of individuals taking vitamin supplements was significantly higher in the $\mathrm{NDNS}_{\mathrm{B}}(42.1 \% ; P<0.001)$ in comparison with the LIDNS $(17 \cdot 1 \%)$ and NDNS $_{\mathrm{NB}}$ sample $(25.1 \%$; Table 1$)$, and in all samples supplement use was strongly associated with serum $25(\mathrm{OH}) \mathrm{D}$ levels.

For all three samples, having a blood sample drawn in the summer, being light skinned, having higher dietary vitamin $\mathrm{D}$ intake and taking vitamin supplements were factors significantly associated with higher serum $25(\mathrm{OH}) \mathrm{D}$ levels in the fully adjusted analyses (Table 2). There was a inverse association between serum $25(\mathrm{OH}) \mathrm{D}$ status and BMI only in the LIDNS sample. Area of residence was only significant for the $\mathrm{NDNS}_{\mathrm{NB}}$ sample where those living in Scotland had the lowest vitamin D status. The relationship between $25(\mathrm{OH}) \mathrm{D}$ and household composition was inconsistent between the samples. Sex and age group did not show significant associations with serum 25(OH)D concentrations (data not shown), and were not presented in the final models.

\section{Discussion}

The present study shows that the low-income/materially deprived population in Britain has lower vitamin D status than the general population. Both the NDNS and the LIDNS surveys were designed to give a representative picture of the nutritional status of the population groups examined. In both surveys, the blood samples were taken after dietary assessments at a separate visit by a nurse. The participants were asked to comply with several measurements in addition to giving blood, which may have contributed to the lower response rate. However, specific statistical weighting was used to attempt to correct for the non-response in addition to unequal sample selection ${ }^{(10,11)}$. The factors shown to affect vitamin D status, i.e. season (light levels), skin type, dietary intake of vitamin $\mathrm{D}$, and intake of dietary supplements, apply to all three samples independently. The question on supplement use was not specified on vitamin $\mathrm{D}$ content, and can to some extent reflect that supplement users have a generally healthier diet and lifestyle.

The current UK recommendation advises a daily vitamin D intake of $10 \mu \mathrm{g}$ (400 IU) to be taken among those aged over 65 years $^{(2)}$. However, the long-term compliance with intake of supplements for larger population groups can be questioned ${ }^{(13)}$. Given the emerging evidence on possible wider health benefits of good vitamin D status and the several studies indicating insufficient vitamin D status across all age groups, it is timely to have a debate on whether there should be more widespread fortification of vitamin D in food $^{(14,15)}$. The national prevention and treatment strategies of vitamin D deficiency and sub-optimal status need to be targeted to include the adult population and the deprived populations particularly, as well as the elderly and ethnic minority populations. 
Table 1. Serum 25-hydroxyvitamin D concentrations (nmol/l) among individuals aged 19-64 years living in private households in the UK from two population surveys: the Low Income Diet and Nutrition Survey (LIDNS) and the National Diet and Nutrition Survey (NDNS)

(Mean values and $95 \%$ confidence intervals)

\begin{tabular}{|c|c|c|c|c|c|c|c|c|c|c|c|c|}
\hline \multirow[b]{2}{*}{ Characteristics } & \multicolumn{4}{|c|}{ LIDNS ( $n$ 792) } & \multicolumn{4}{|c|}{ NDNS sample receiving benefits ( $n$ 243) } & \multicolumn{4}{|c|}{ NDNS sample not receiving benefits ( $n$ 1054) } \\
\hline & $n$ & Mean & $95 \% \mathrm{Cl}$ & $P \dagger$ & $n$ & Mean & $95 \% \mathrm{Cl}$ & $P \dagger$ & $n$ & Mean & $95 \% \mathrm{Cl}$ & $P \dagger$ \\
\hline All & & $46 \cdot 5^{\star}$ & $44 \cdot 0,49 \cdot 0$ & & & $43 \cdot 0^{\star *}$ & $39 \cdot 7,46 \cdot 3$ & & & $50 \cdot 1$ & $48 \cdot 6,51 \cdot 7$ & \\
\hline Sex & & & & 0.4 & & & & 0.7 & & & & 0.3 \\
\hline Men & 246 & $45 \cdot 1$ & $40 \cdot 7,49 \cdot 4$ & & 84 & $42 \cdot 3$ & $37 \cdot 1,47 \cdot 4$ & & 508 & $49 \cdot 2$ & $47 \cdot 0,51 \cdot 4$ & \\
\hline Women & 546 & $47 \cdot 2$ & $44 \cdot 3,50 \cdot 1$ & & 159 & 43.5 & $39 \cdot 2,47 \cdot 7$ & & 546 & $51 \cdot 1$ & $48 \cdot 8,53 \cdot 3$ & \\
\hline Age group (years) & & & & 0.5 & & & & 0.6 & & & & 0.2 \\
\hline $19-34$ & 233 & $47 \cdot 0$ & $42 \cdot 6,51 \cdot 3$ & & 99 & $42 \cdot 3$ & $37 \cdot 2,47 \cdot 4$ & & 264 & $49 \cdot 2$ & $45 \cdot 9,52 \cdot 5$ & \\
\hline $35-49$ & 312 & 47.5 & $43 \cdot 9,51 \cdot 1$ & & 105 & $43 \cdot 0$ & $38 \cdot 2,47 \cdot 8$ & & 436 & $49 \cdot 0$ & $46 \cdot 8,51 \cdot 1$ & \\
\hline $50-64$ & 247 & 44.5 & $40 \cdot 2,48 \cdot 8$ & & 39 & $44 \cdot 7$ & $36 \cdot 8,52 \cdot 6$ & & 354 & $52 \cdot 4$ & $49 \cdot 9,54 \cdot 8$ & \\
\hline Region $\ddagger$ & & & & $0.3 \S$ & & & & $0.04 \S$ & & & & $0.005 \S$ \\
\hline Scotland & 75 & $44 \cdot 2$ & $35 \cdot 9,52 \cdot 5$ & & 22 & 37.7 & $30 \cdot 7,44 \cdot 6$ & & 73 & 44.4 & $39 \cdot 3,49 \cdot 5$ & \\
\hline Northern & 220 & $49 \cdot 3$ & $44 \cdot 6,54 \cdot 0$ & & 83 & $46 \cdot 8$ & $40 \cdot 8,52 \cdot 8$ & & 255 & $53 \cdot 1$ & $49 \cdot 8,56 \cdot 4$ & \\
\hline South/Central/Wales & 365 & 45.5 & $42 \cdot 2,48 \cdot 8$ & & 138 & 41.4 & $37 \cdot 2,45 \cdot 7$ & & 726 & $49 \cdot 7$ & $47 \cdot 8,51 \cdot 6$ & \\
\hline Northern Ireland & 132 & $46 \cdot 1$ & $41 \cdot 5,50 \cdot 8$ & & - & - & & & - & - & & \\
\hline Season & & & & $<0.001$ & & & & $<0.001$ & & & & $<0.001$ \\
\hline January-March & 193 & $39 \cdot 1$ & $35 \cdot 2,42 \cdot 9$ & & 66 & 31.5 & $28 \cdot 0,35 \cdot 0$ & & 242 & $42 \cdot 8$ & $39.9,45 \cdot 8$ & \\
\hline April-June & 233 & $43 \cdot 7$ & $39.5,47.9$ & & 72 & 42.5 & $37 \cdot 0,48 \cdot 1$ & & 352 & $46 \cdot 6$ & $44.4,48.9$ & \\
\hline July-September & 202 & $58 \cdot 6$ & $52 \cdot 9,64 \cdot 4$ & & 51 & 60.5 & $51 \cdot 5,69 \cdot 5$ & & 216 & $68 \cdot 7$ & $65 \cdot 2,72 \cdot 1$ & \\
\hline October-December & 164 & 47.5 & $42 \cdot 3,52 \cdot 6$ & & 54 & 39.9 & $34.9,44.9$ & & 244 & $45 \cdot 8$ & $42 \cdot 9,48 \cdot 7$ & \\
\hline Ethnic group & & & & $<0.001$ & & & & $<0.001$ & & & & $<0.001$ \\
\hline White & 728 & $49 \cdot 0$ & $46 \cdot 3,51 \cdot 6$ & & 221 & 44.5 & $41 \cdot 1,47 \cdot 9$ & & 1008 & 51.4 & $49 \cdot 8,53 \cdot 0$ & \\
\hline Non-white & 64 & 29.9 & $25 \cdot 9,33.9$ & & 22 & 27.5 & $21 \cdot 9,33 \cdot 2$ & & 46 & $26 \cdot 4$ & $22 \cdot 1,30 \cdot 6$ & \\
\hline Household composition|| & & & & $<0.01$ & & & & 0.05 & & & & 0.2 \\
\hline a & 233 & $44 \cdot 2$ & $39.8,48 \cdot 6$ & & 42 & $37 \cdot 1$ & $31 \cdot 3,42 \cdot 9$ & & 212 & $49 \cdot 7$ & $46 \cdot 5,52 \cdot 8$ & \\
\hline b & 133 & $45 \cdot 3$ & $40 \cdot 2,50 \cdot 4$ & & 43 & $39 \cdot 2$ & $32 \cdot 7,45 \cdot 6$ & & 519 & $51 \cdot 1$ & $48 \cdot 9,53 \cdot 3$ & \\
\hline c & 260 & 53.5 & $49 \cdot 3,57 \cdot 8$ & & 83 & $48 \cdot 3$ & $43 \cdot 5,53 \cdot 0$ & & 26 & $40 \cdot 2$ & $33 \cdot 3,47 \cdot 2$ & \\
\hline $\mathrm{d}$ & 166 & $43 \cdot 0$ & $38 \cdot 4,47 \cdot 6$ & & 75 & $44 \cdot 0$ & $38 \cdot 0,50 \cdot 0$ & & 297 & $48 \cdot 7$ & $45 \cdot 9,51 \cdot 4$ & \\
\hline $\mathrm{BMI}\left(\mathrm{kg} / \mathrm{m}^{2}\right)$ & & & & 0.03 & & & & 0.8 & & & & 0.07 \\
\hline $18.5-24.9$ & 296 & $49 \cdot 3$ & $45 \cdot 1,53 \cdot 5$ & & 108 & $42 \cdot 0$ & $37.5,46.5$ & & 423 & $50 \cdot 1$ & $47 \cdot 6,52 \cdot 6$ & \\
\hline$\geq 25-29 \cdot 9$ & 240 & $47 \cdot 3$ & $43 \cdot 5,51 \cdot 2$ & & 92 & $43 \cdot 6$ & $37 \cdot 8,49 \cdot 3$ & & 400 & $53 \cdot 0$ & $50 \cdot 4,55 \cdot 7$ & \\
\hline$\geq 30-34.9$ & 124 & 41.8 & $36 \cdot 5,47 \cdot 1$ & & 23 & $47 \cdot 6$ & $39.8,55 \cdot 3$ & & 169 & $45 \cdot 2$ & $42 \cdot 2,48 \cdot 2$ & \\
\hline$\geq 35$ & 89 & $43 \cdot 8$ & $37.7,49.9$ & & 20 & $40 \cdot 4$ & $27 \cdot 2,53 \cdot 6$ & & 62 & $45 \cdot 4$ & $37 \cdot 6,53 \cdot 1$ & \\
\hline Vitamin D intake from food $(\mu \mathrm{g} / \mathrm{d}) \boldsymbol{q}$ & & & & 0.0009 & & & & $<0.0001$ & & & & $<0.0001$ \\
\hline $0.1-1.7$ (Lowest) & 264 & $40 \cdot 6$ & $36 \cdot 8,44 \cdot 4$ & & 74 & $35 \cdot 1$ & $30 \cdot 7,39 \cdot 4$ & & 336 & 44.9 & $42 \cdot 0,47 \cdot 8$ & \\
\hline 1.7-2.9 (Middle) & 264 & $49 \cdot 8$ & $45 \cdot 2,54 \cdot 3$ & & 75 & $42 \cdot 9$ & $37 \cdot 3,48 \cdot 6$ & & 336 & $52 \cdot 9$ & $50 \cdot 1,55 \cdot 6$ & \\
\hline 2.9-32.4 (Highest) & 264 & 49.9 & $45 \cdot 9,54 \cdot 0$ & & 75 & $50 \cdot 0$ & $44 \cdot 0,56 \cdot 0$ & & 336 & $53 \cdot 5$ & $50 \cdot 9,56 \cdot 2$ & \\
\hline Taking vitamin supplements & & & & 0.001 & & & & 0.0006 & & & & 0.002 \\
\hline Yes & 154 & 54.5 & $49 \cdot 3,59 \cdot 8$ & & 61 & 54.6 & $46 \cdot 6,62 \cdot 7$ & & 444 & 53.1 & & \\
\hline No & 638 & 44.9 & $42 \cdot 1,47 \cdot 6$ & & 182 & $39 \cdot 3$ & $36 \cdot 0,42 \cdot 6$ & & 610 & $48 \cdot 1$ & & \\
\hline
\end{tabular}

Mean value was significantly different from that for the NDNS sample not receiving benefits: ${ }^{\star} P<0.05,{ }^{\star \star} P<0.001$

$\dagger$ Test for a linear trend.

Different regional grouping in the two studies as the NDNS was carried out only in mainland Britain

$\S$ Test for heterogeneity.

NDNS: a, living alone; b, with spouse or partner, other adults, no dependent children; $c$, with dependent children, no spouse; $d$, with dependent children, with spouse. LIDNS: a, one adult of working age or one adult of retirement age; b, two or more adults, at least one of working age or two or more adults, all of retirement age; c, one adult, one or more children; $d$, two or more adults, one or more children.

In thirds. For the NDNS, the vitamin D intake ( $\mu \mathrm{g} / \mathrm{d})$ range for those who received benefits is $0.18-1.67,1.70-2.78$ and $2.79-26.84$ for the lowest, middle and highest thirds respectively; the vitamin $\mathrm{D}$ intake ( $\mu \mathrm{g} / \mathrm{d}$ ) range for those not receiving benefits is $0.04-2 \cdot 22,2 \cdot 22-3 \cdot 73$ and $3 \cdot 70-22 \cdot 10$ for the lowest, middle and highest thirds respectively. 
Table 2. Adjusted* regression coefficients (ARC) for serum 25-hydroxyvitamin concentrations (nmol/l) by associated risk factors and sex aged $19-64$ years living in private households from the Low Income Diet and Nutrition Survey (LIDNS) and National Diet and Nutrition Survey (NDNS)

(Adjusted regression coefficients and $95 \%$ confidence intervals)

\begin{tabular}{|c|c|c|c|c|c|c|c|c|c|}
\hline \multirow[b]{2}{*}{ Risk factors } & \multicolumn{3}{|c|}{ LIDNS ( $n$ 792) } & \multicolumn{3}{|c|}{$\begin{array}{l}\text { NDNS sample receiving benefits } \\
\text { ( }(n 243)\end{array}$} & \multicolumn{3}{|c|}{$\begin{array}{l}\text { NDNS not receiving benefits } \\
\qquad(n 1054)\end{array}$} \\
\hline & ARC & $95 \% \mathrm{Cl}$ & $P \dagger$ & ARC & $95 \% \mathrm{Cl}$ & $P \dagger$ & ARC & $95 \% \mathrm{Cl}$ & $P \dagger$ \\
\hline Season & \multirow{2}{*}{\multicolumn{2}{|c|}{ Reference }} & $<0.001$ & & & 0.001 & & & $<0.001$ \\
\hline January-March & & & & \multicolumn{2}{|c|}{ Reference } & & \multicolumn{2}{|c|}{ Reference } & \\
\hline April-June & $6 \cdot 2$ & $0.5,11.9$ & & $6 \cdot 1$ & $-0.3,13.0$ & & $2 \cdot 3$ & $-1.5,6 \cdot 0$ & \\
\hline July-September & 21.4 & $15 \cdot 3,27 \cdot 5$ & & $26 \cdot 2$ & $18 \cdot 3,34 \cdot 0$ & & $25 \cdot 1$ & $20 \cdot 6,29 \cdot 5$ & \\
\hline October-December & $9 \cdot 6$ & $3.5,15 \cdot 6$ & & $6 \cdot 8$ & $0.5,13 \cdot 1$ & & 3.6 & $-0.4,7.6$ & \\
\hline Region $\ddagger$ & & & & & & 0.08 & & & 0.03 \\
\hline Scotland & \multicolumn{2}{|l|}{-} & & \multicolumn{2}{|c|}{ Reference } & & \multicolumn{2}{|c|}{ Reference } & \\
\hline Northern & - & & & 6.9 & $-0.8,14.5$ & & $5 \cdot 8$ & $0.2,11.4$ & \\
\hline Central/Midlands/Wales/South (London) & - & & & $2 \cdot 8$ & $-4 \cdot 4,10 \cdot 0$ & & $3 \cdot 0$ & $-1 \cdot 9,8 \cdot 0$ & \\
\hline Ethnicity & & & $<0.001$ & & & $<0.0001$ & & & $<0.0001$ \\
\hline Non-white & \multicolumn{2}{|c|}{ Reference } & & \multicolumn{2}{|c|}{ Reference } & & \multicolumn{2}{|c|}{ Reference } & \\
\hline White & $20 \cdot 1$ & $15 \cdot 2,25 \cdot 1$ & & $17 \cdot 1$ & $8 \cdot 7,25 \cdot 6$ & & $21 \cdot 2$ & $16 \cdot 7,25 \cdot 8$ & \\
\hline Household composition§ & & & 0.02 & & & 0.003 & & & 0.7 \\
\hline a & \multicolumn{2}{|c|}{ Reference } & & \multicolumn{2}{|c|}{ Reference } & & \multicolumn{2}{|c|}{ Reference } & \\
\hline b & $2 \cdot 8$ & $-4 \cdot 0,9 \cdot 7$ & & $3 \cdot 2$ & $-3 \cdot 6,10 \cdot 0$ & & $2 \cdot 2$ & $-1 \cdot 3,5 \cdot 7$ & \\
\hline c & 8.5 & $3 \cdot 0,13 \cdot 9$ & & $12 \cdot 1$ & $5 \cdot 7,18 \cdot 5$ & & $-4 \cdot 8$ & $-11 \cdot 3,1 \cdot 7$ & \\
\hline d & 1.8 & $-3 \cdot 4,7 \cdot 0$ & & $7 \cdot 6$ & $0.5,14.7$ & & 3.1 & $-0.7,6.9$ & \\
\hline BMI $\left(\mathrm{kg} / \mathrm{m}^{2}\right)$ & -0.6 & $-0.9,-0.2$ & 0.009 & -0.02 & $-0.4,0.3$ & 0.9 & -0.1 & $-0.3,0.2$ & 0.8 \\
\hline Vitamin D intake from food $(\mu \mathrm{g} / \mathrm{d}) \|$ & & & 0.05 & & & 0.0005 & & & 0.004 \\
\hline $0.1-1.7$ (Lowest) & \multicolumn{2}{|c|}{ Reference } & & \multicolumn{2}{|c|}{ Reference } & & \multicolumn{2}{|c|}{ Reference } & \\
\hline $1.7-2 \cdot 9$ (Middle) & $6 \cdot 7$ & $1.4,12 \cdot 1$ & & $5 \cdot 2$ & $-0.7,11 \cdot 1$ & & $5 \cdot 5$ & $2 \cdot 1,9 \cdot 0$ & \\
\hline 2.9-32.4 (Highest) & $5 \cdot 2$ & $0.0,10.3$ & & $12 \cdot 8$ & $7 \cdot 0,18 \cdot 7$ & & 8.2 & $4.8,11 \cdot 6$ & \\
\hline Taking vitamin supplements & & & 0.004 & & & 0.002 & & & $<0.001$ \\
\hline No & \multicolumn{2}{|c|}{ Reference } & & \multicolumn{2}{|c|}{ Reference } & & \multicolumn{2}{|c|}{ Reference } & \\
\hline Yes & 8.4 & $2 \cdot 6,14 \cdot 3$ & & 9.9 & $3 \cdot 0,16 \cdot 9$ & & $5 \cdot 6$ & $2 \cdot 8,8 \cdot 4$ & \\
\hline
\end{tabular}

${ }^{*}$ Adjusted for all factors listed above.

†Test for a linear trend.

¥Region was not associated with vitamin D status in the LIDNS sample.

§NDNS: a, living alone; b, with spouse or partner, other adults, no dependent children; c, with dependent children, no spouse; d, with dependent children, with spouse. LIDNS: $\mathrm{a}$, one adult of working age or one adult of retirement age; b, two or more adults, at least one of working age or two or more adults, all of retirement age; c, one adult, one or more children; $d$, two or more adults, one or more children.

$\|$ In thirds. For the NDNS, the vitamin D intake ( $\mu \mathrm{g} / \mathrm{d})$ range for those who received benefits is $0.18-1.67,1.70-2.78$ and $2.79-26.84$ for the lowest, middle and highest thirds respectively; the vitamin D intake $(\mu \mathrm{g} / \mathrm{d})$ range for those not receiving benefits is $0.04-2 \cdot 22,2 \cdot 22-3.73$ and $3 \cdot 70-22 \cdot 10$ for the lowest, middle and highest thirds respectively.

\section{Acknowledgements}

The NDNS survey was approved by the South Thames Multicentre Research Ethics Committee (MREC) and National Health Service Local Research Ethics Committees (LRECs). The LIDNS survey was approved by the North London MREC. Participants providing a blood sample gave written consent.

The NDNS programme is commissioned jointly by the Food Standards Agency (FSA) and the Department of Health while LIDNS was funded by the FSA. Data analysis and interpretation was done by the authors independently of the funding sources based on the available data. The corresponding author had full access to the survey data and had final responsibility for the decision to submit for publication.

In terms of funding, the NDNS programme is commissioned jointly by the Food Standards Agency (FSA) and the Department of Health, and conducted by the Office for National Statistics and the MRC Human Nutrition Research. LIDNS was funded by the FSA and conducted by the National Centre for Social Research, in collaboration with researchers from King's College London and University College London. Data analysis and interpretation were done by the authors independently of the funding sources based on the available data.
On the sponsor's role, the funding body played no role in the formulation of the design, methods, subject recruitment, data collection, analysis, or preparation of this paper.

V. H. initiated the idea of the paper, carried out the literature review, interpreted the results, and drafted the manuscript. A. H. contributed to the design of the analysis, the interpretation of results, and revised the manuscript. G. M. designed and conducted the analyses, interpreted the results, and revised the paper. G. M. had full access to the survey data and had final responsibility to submit for publication. The authors have no conflicts of interest to declare.

\section{References}

1. Holick MF (2004) Sunlight and vitamin D for bone health and prevention of autoimmune diseases, cancers, and cardiovascular disease. Am J Clin Nutr 80, 1678S-1688S.

2. Scientific Advisory Committee on Nutrition (2007) Scientific Advisory Committee on Nutrition Update on Vitamin D. London: The Stationery Office.

3. Henderson L, Irving K, Gregory J, Bates CJ, Prentice A, Perks J, Swan G \& Farron M (2003) The National Diet and Nutrition Survey: Adults Aged 19 to 64 Years, Vol. 3, Vitamin and Mineral Intake and Urinary Analytes. London: The Stationery Office. 
4. Das G, Crocombe S, McGrath M, Berry JL \& Mughal MZ (2006) Hypovitaminosis D among healthy adolescent girls attending an inner city school. Arch Dis Child 91, 569-572.

5. Ladhani S, Srinivasan L, Buchanan C \& Allgrove J (2004) Presentation of vitamin D deficiency. Arch Dis Child 89, 781-784.

6. Pal BR, Marshall T, James C \& Shaw NJ (2003) Distribution analysis of vitamin D highlights differences in population subgroups, preliminary observations from a pilot study in UK adults. J Endocrinol 179, 119-129.

7. Stephens WP, Klimiuk PS, Berry JL \& Mawer EB (1981) Annual high-dose vitamin D prophylaxis in Asian immigrants. Lancet ii, 1199-1202.

8. Hypponen E \& Power C (2007) Hypovitaminosis D in British adults at age $45 \mathrm{y}$, nationwide cohort study of dietary and lifestyle predictors. Am J Clin Nutr 85, 860-868.

9. Department of Health (1988) Nutrition and Bone Health, with Particular Reference to Calcium and Vitamin D. London: The Stationery Office.

10. Nelson M, Erens B, Bates B, Church S \& Boshier T (2007) Low Income Diet and Nutrititon Survey. Volume 1. Background, Methods, Sample Characteristics. London: The Stationery Office.
11. The Food Standards Agency (2004) The National Diet and Nutrition Survey, adults aged 19 to 64 years. Technical Report. http://www.food.gov.uk/science/dietarysurveys/ndnsdo cuments/ (accessed 12 May 2008).

12. Ruston D, Hoare J, Henderson L, Gregory J, Bates CJ, Prentice A, Birch M, Swan G \& Farron M (2004) National Diet and Nutrition Survey: Adults Aged 19 to 64 Years, Vol. 4, Nutritional Status (Anthropometry and Blood Analytes), Blood Pressure and Physical Activity. London: The Stationery Office.

13. Grant AM, Avenell A, Campbell MK, et al. (2005) Oral vitamin $\mathrm{D}_{3}$ and calcium for secondary prevention of low-trauma fractures in elderly people (Randomised Evaluation of Calcium Or vitamin D, RECORD), a randomised placebo-controlled trial. Lancet 365, 1621-1628.

14. Heaney RP (2007) Bone health. Am J Clin Nutr 85, 300S-303S.

15. Tylavsky FA, Cheng S, Lyytikäinen A, Viljakainen $\mathrm{H}$ \& Lamberg-Allardt C (2006) Strategies to improve vitamin D status in northern European children, exploring the merits of vitamin D fortification and supplementation. J Nutr 136, $1130-1134$. 